\title{
Small Biogas Plant Stability Prediction Model
}

\author{
Vedrana JERKOVIĆ ŠTIL, Željko ŠPOLJARIĆ, Željko HEDERIĆ
}

\begin{abstract}
In this paper stability prediction for a small biogas plant in islanded mode depending on local consumers energy consumption growth is given. Biogas plant with two cogeneration facilities and local consumers is tested for on grid and islanded operation and thus represents a microgrid. Generator and regulator modelling as well as surrounding electrical grid modelling in software package Power World Simulator are described. Expected consumption growth through the period of 20 years in microgrid area is simulated. All generator important variables, i.e. voltage, frequency, real and reactive power in case of islanded mode are examined and explained. Finally, stability prediction analysis of biogas plant and surrounding consumers for 20 years period is given.
\end{abstract}

Keywords: biogas plant; consumption growth; islanded mode; microgrid; stability; synchronous generator

\section{INTRODUCTION}

Renewable energy sources include biomass, hydropower, geothermal, solar, wind and marine energies [1]. The energy potentials of most organic substances, commonly known as biomass, are becoming more important when considering the inconsistent and expensive supplies of fossil fuels [2]. Biogas is the combustible gas produced in a process of anaerobic digestion. According to [3], its physical and chemical properties are close to those of natural gas, although with lower methane content. This means that biogas can be used to boil water or for cooking instead of LPG, used as a fuel for process heating, used for lighting purpose, produce electricity via internal combustion engine or used in replacement of diesel or gasoline to drive machines. Electrical energy production process from biogas is shown in Fig. 1. A long-term operation of a small biogas/diesel dual-fuel engine for on-farm electricity production was tested in [4]. Authors concluded that the dual-fuel engine has great potential for useful on-farm energy utilization.

The increasing number of renewable energy sources and distributed generators requires new strategies for the operation and management for the electricity grid in order to maintain or even to improve the power-supply reliability and quality [5]. Today, in case of power system blackout, all these distributed generators also must be disconnected, i.e. their energy production and distribution must be terminated. To maximize the integration of such distributed power sources, their stabile operation in islanded mode is nowadays being developed. A new concept of microgrid, which refers to a small-scale power system with a cluster of loads and distributed generators operating together with energy management, control and protection devices and associated software [6], is being introduced. A survey of various islanding protection schemes, which are being developed to enable microgrid operation in case of blackout, is given in [7]. Possible improvements of islanded mode stability by introducing active power filters and static VAR compensators in grid are explained in [8]. In [9] authors report successful testing of innovative relay prototype for detection grid connected and islanded operation. To make islanded microgrid operation even more reliable, energy resource scheduling multi-agent system is proposed in [10]. Small signal stability of such microgrids is analyzed in [11]. Intentional islanding and microgrid experience around the world is explained in [12].

Stability testing of a microgrid represented by a small biogas plant comprised of two cogeneration facilities together with local consumers connected to electrical grid in sense of sudden disturbances is given in [13]. It is shown that tested microgrid can efficiently operate in islanded mode in case of blackout. All these results brought another interesting question: how long would it be possible to supply local consumers in case of blackout taking into account energy consumption growth through the years.

The goal of this paper is to forecast how long production of a small biogas plant containing two cogeneration facilities would be sufficient to supply local consumers in case of blackout, i.e. islanded mode. Here, stability testing will be carried out by comprising models of generator, driving machine, control units and electrical grid together with modelling of energy consumption growth. The gained system will be simulated and stability assessment based on simulation results will be given. The simulation results would be further analysed in the meaning of the frequency gradient protection.

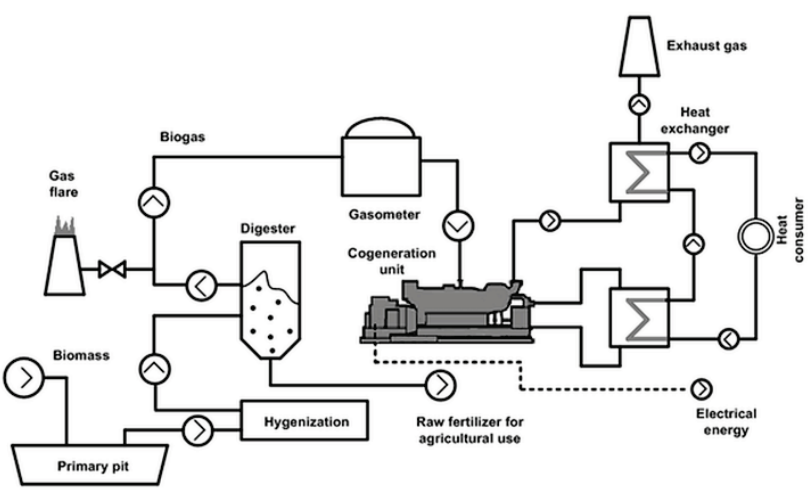

Figure 1 Electrical energy production from biogas [13]

\section{BIOGAS PLANT MODELLING}

Biogas plant analysed in this paper consists of two cogeneration facilities. Each cogeneration facility consists of internal combustion engine and synchronous generator, as shown in Fig. 2. Automatic regulation of cogeneration facility can be divided in two separate control loops. The 
first control loop is used for speed regulation of internal combustion engine and thus synchronous generator. This control loop consists of engine, actuator that affects biogas flow and speed controller, i.e. Governor. The other control loop is used for voltage control of synchronous generator. The main controller of this loop is Automatic Voltage Regulator - AVR, which regulates generator output voltage. AVR is very effective during steady-state operation, but, as pointed out in [14], in case of sudden disturbances it may have negative influence on damping of the power swings, because it forces field current changes in the generator. This is eliminated by introducing a supplementary controller, the Power System Stabilizer - PSS, which produces an additional signal into control loop and in that way compensates power oscillations. Typically, the higher-level decision-making units perform logical checks that identify plant mode of operation and activate the corresponding lower level unit; the activated lower level unit then executes continuous actions for the identified plant operating mode [15]. In case of cogeneration facility, reference values for governor and AVR are generated in master control unit, which contains functions for protection and synchronous generator synchronization to the electrical grid.

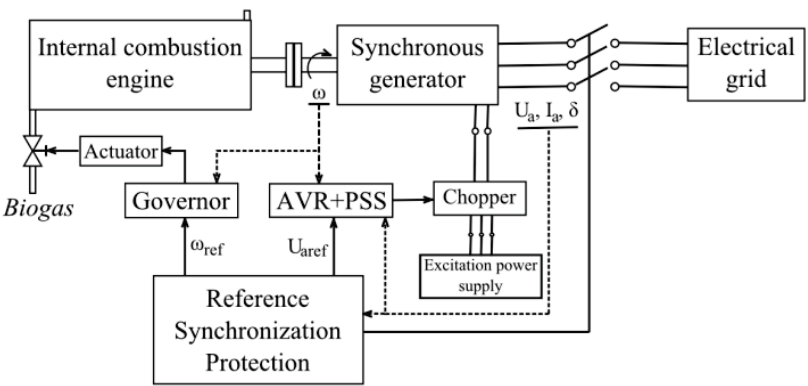

Figure 2 Biogas cogeneration facility block scheme

The power system stability definition and classification in accordance with new technologies and controls, as well as with the operation in highly stressed conditions is explained in [16]. The simplest way to test facility stability is to model one facility containing synchronous generator connected to the infinite bus. The main drawback of this model is that no changes in electrical grid, such as load change and local power oscillations between neighbouring facilities can be simulated. In this paper microgrid will be modelled as multimachine model containing two cogeneration facilities, local consumers and transformers. Modelling and simulation is carried out in Power World Simulator. In rest of the section each part of cogeneration facility and electrical grid will be described in detail.

\subsection{Voltage Regulation System Model}

Generating unit used in cogeneration facility is 1,45 MVA salient pole synchronous generator. Regulation in generator excitation circuit consists of AVR and additional VAR/power-factor controller. According to [17], VAR/power-factor controller is important for smaller generators synchronized to stiff utility bus, because system voltage will not change as the smaller generator shares reactive loading. If the system voltage changes significantly, AVR of a smaller generator would try to keep the reference voltage. This would lead to over or under excitation of the smaller generator. VAr/powerfactor controller output is added to input of the AVR. For simulation the Power World third order linear synchronous generator model "GENSAL" is used with generator parameters given in the Tab. 1. It is important to notice that generator parameters are given in per unite system base apparent power of $1550 \mathrm{kVA}$. Excitation system is modelled using "SEXS_GE" that comprises AVR and the generator excitation, with the transfer function given in the Eq. (1):

$$
G_{R}(s)=K_{C} \frac{1+T_{C} s}{T_{C} s}
$$

PI-controller assures that there is no generator output voltage offset in steady state operation. Power World "PFQRG" stabilizer is chosen for VAr/power-factor controller modelling, which is set to $\cos$ phi $=1$. Here, regulation with PI-controller given in Eq. (1) is also achieved. Input signals are the reference power factor and the generator power factor.

Table 1 Generator parameters

\begin{tabular}{|c|c|c|c|c|c|}
\hline Parameter Name & Symbol & Value & Parameter Name & Symbol & Value \\
\hline Nominal voltage / V & $U_{\mathrm{n}}$ & 400 & Direct axis reactance / pu & $X_{\mathrm{d}}$ & 2,96 \\
\hline Nominal apparent power / kVA & $S_{\mathrm{n}}$ & 1445 & Transient axis reactance / pu & $X_{\mathrm{d}}^{\prime}$ & 0,18 \\
\hline Nominal power factor & $\cos \varphi_{\mathrm{n}}$ & 0,8 & Subtransient axis reactance / pu & $X^{\prime \prime}{ }_{\mathrm{d}}$ & 0,13 \\
\hline Nominal speed / rpm & $n_{\mathrm{n}}$ & 1500 & Quadrature axis reactance / pu & $X_{\mathrm{q}}$ & 1,91 \\
\hline Transient direct time constant, closed armature / s & $T_{\mathrm{d}}^{\prime}$ & 0,135 & Leakage reactance / pu & $X_{1}$ & 0,03 \\
\hline Transient direct time constant, open armature / s & $T^{\prime}{ }_{\mathrm{d} 0}^{\prime}$ & 2,23 & Moment of inertia $/ \mathrm{kgm}^{2}$ & $J$ & 36,33 \\
\hline
\end{tabular}

\subsection{Speed Regulation System Model}

Speed regulation system is modelled according to driving machine coupled with the generator. Driving machines for synchronous generators are mainly turbines and internal combustion engines. Proper regulation of synchronous generator driving machine contributes to the stability of plant and surrounding power system. Control of a steam turbine operation is given in [18]. Driving machine in simulated cogeneration facility is internal combustion engine supplied with the biogas. This type of motor, along with an actuator and a governor, is described in the Power World Library model "DEGOV". Integral nature of the actuator assures zero frequency offset at a steady state. The governor is therefore a proportional controller tuned to achieve the minimal oscillations during a transition state and thus maximizes transient stability of the simulated cogeneration facility. 


\section{ELECTRICAL GRID AND ENERGY CONSUMPTION GROWTH MODELLING}

The electrical grid simulation model gives a possibility to test the transient stability of a system in case of various disturbances such as bus opening, bus closing, generator outages, short circuits, etc. In this model it is also possible to implement energy consumption growth for each modelled load.

\subsection{Electrical Grid Modelling}

The electrical grid model contains consumers and transformers nearest to the biogas plant. The rest of the grid beginning with the nearest $35 \mathrm{kV}$ bus is modelled as an infinite bus, as shown in Fig. 3. The biogas plant is presented with two 1,45 MVA generators modelled as explained in subsection 2.1. Islanded operation of the modelled microgrid is obtained by disconnecting the infinite bus.

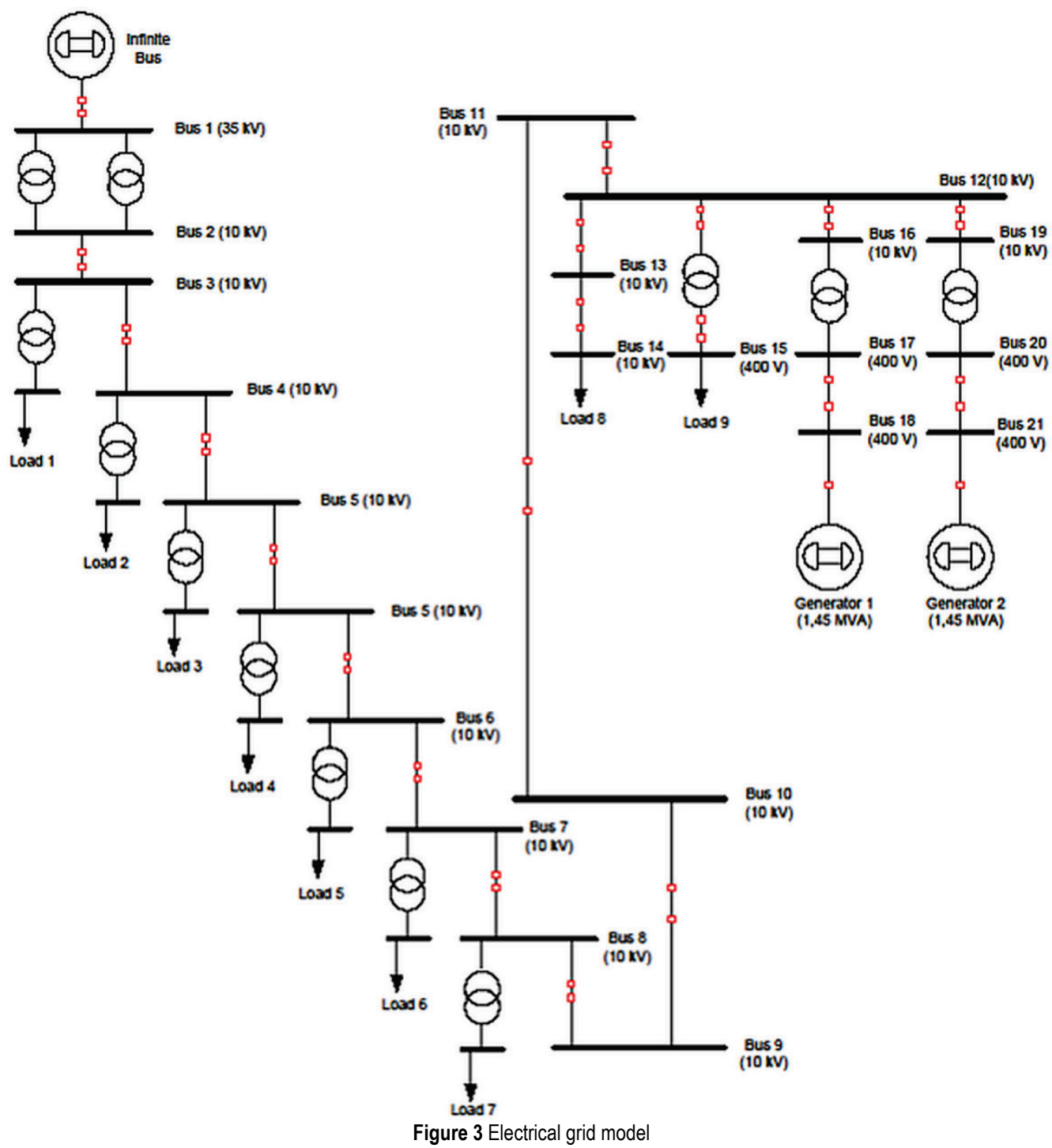

Table 2 Consumption growth in five year periods

\begin{tabular}{|c|c|c|c|c|c|c|c|c|c|c|c|c|c|}
\hline Year & start & 5th & 10th & 15 th & 20th & Year & start & 5th & 10th & 15 & 20th \\
\hline & \multicolumn{9}{|c|}{ Active power / MW } & \multicolumn{4}{|c|}{ Reactive power / MVAr } \\
\hline Load 1 & 0,14 & 0,16 & 0,19 & 0,23 & 0,27 & Load 1 & 0,29 & 0,34 & 0,40 & 0,47 & 0,55 \\
\hline Load 2 & 0,13 & 0,15 & 0,18 & 0,21 & 0,25 & Load 2 & 0,12 & 0,14 & 0,17 & 0,19 & 0,23 \\
\hline Load 3 & 0,24 & 0,28 & 0,33 & 0,39 & 0,46 & Load 3 & 0,01 & 0,01 & 0,01 & 0,02 & 0,02 \\
\hline Load 4 & 0,10 & 0,12 & 0,14 & 0,16 & 0,19 & Load 4 & 0,00 & 0,00 & 0,00 & 0,00 & 0,00 \\
\hline Load 5 & 0,24 & 0,28 & 0,33 & 0,39 & 0,46 & Load 5 & 0,00 & 0,00 & 0,00 & 0,00 & 0,00 \\
\hline Load 6 & 0,15 & 0,18 & 0,21 & 0,24 & 0,29 & Load 6 & 0,00 & 0,00 & 0,00 & 0,00 & 0,00 \\
\hline Load 7 & 0,05 & 0,06 & 0,07 & 0,08 & 0,10 & Load 7 & 0,00 & 0,00 & 0,00 & 0,00 & 0,00 \\
\hline Load 8 & 0,17 & 0,20 & 0,23 & 0,28 & 0,32 & Load 8 & 0,08 & 0,09 & 0,11 & 0,13 & 0,15 \\
\hline Load 9 & 0,37 & 0,43 & 0,51 & 0,60 & 0,71 & Load 9 & 0,08 & 0,09 & 0,11 & 0,13 & 0,15 \\
\hline
\end{tabular}




\subsection{Energy Consumption Growth Modelling}

According to [1], renewable energy sources supplied around $14 \%$ of the total world energy demand in 2011. By the end of 2016, this ratio rose up to $24,5 \%$ [19]. To forecast electricity demands in short term, medium term and long term periods, energy models are developed. [20] represents a review of various energy demand forecasting models, such as time series, regression, econometric, autoregressive integrated moving average, soft computing techniques, support vector regression, ant colony and particle swarm optimization. Energy consumption forecasts using artificial neural networks for Greece and Turkey are given in [21] and [22] respectively. Energy consumption prediction for nine Central and Eastern European countries depending on financial development
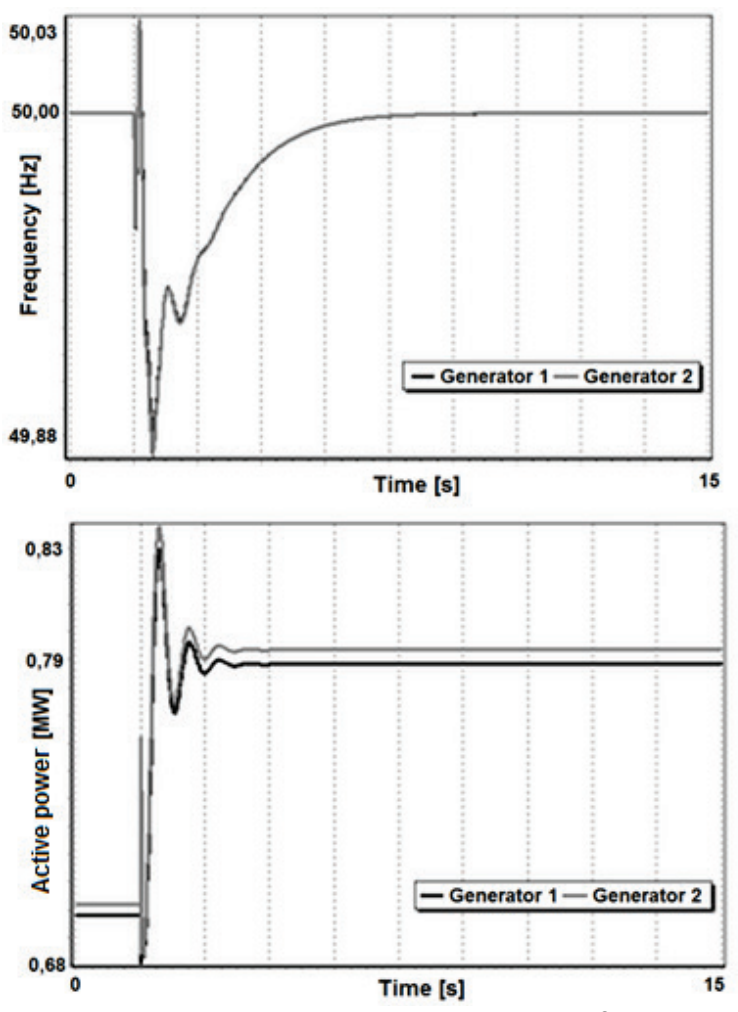

Figure 4 Simulation results for the starting year

\section{SIMULATION RESULTS AND DISCUSSION}

Simulation was carried out for the case of the infinite bus blackout at the simulation time $0,5 \mathrm{~s}$. As models of two cogeneration facilities in biogas plants are identical, operating points of two generators are chosen so they slightly differ. Starting active power is set to $0,695 \mathrm{MW}$ for the Generator 1 and to $0,705 \mathrm{MW}$ for the Generator 2 . For transient stability simulation the Power World Simulator Transient Stability Add on is used. Frequency, active power and reactive power dynamics of the Generator 1 and the Generator 2, as well as voltages of the Bus 12 (nearest to the biogas plant) and the Bus 3 (furthest of the biogas plant) are observed. Consumer loads are increased in each simulation in accordance with Tab. 2.

Simulation results for the starting year are shown in Fig. 4. Before blackout, both generators work in capacitive mode (negative reactive powers). After the is given in [23]. All these studies show that further energy consumption growth can be expected.

Since the object of this paper is a small part of the electric power system, energy consumption growth for the $i^{\text {th }}$ year is modelled by geometric progression for real and reactive power:

$$
\begin{aligned}
& p_{i}=1,035 \cdot p_{i-1}, i=2 \ldots 20 \\
& q_{i}=1,035 \cdot q_{i-1}, i=2 \ldots 20
\end{aligned}
$$

Analogous to [24] the expected annual energy consumption growth rate taken into account is 3,5\%. Prediction period is 20 years. Consumption growth presented in the five year periods is given in Tab. 2 .
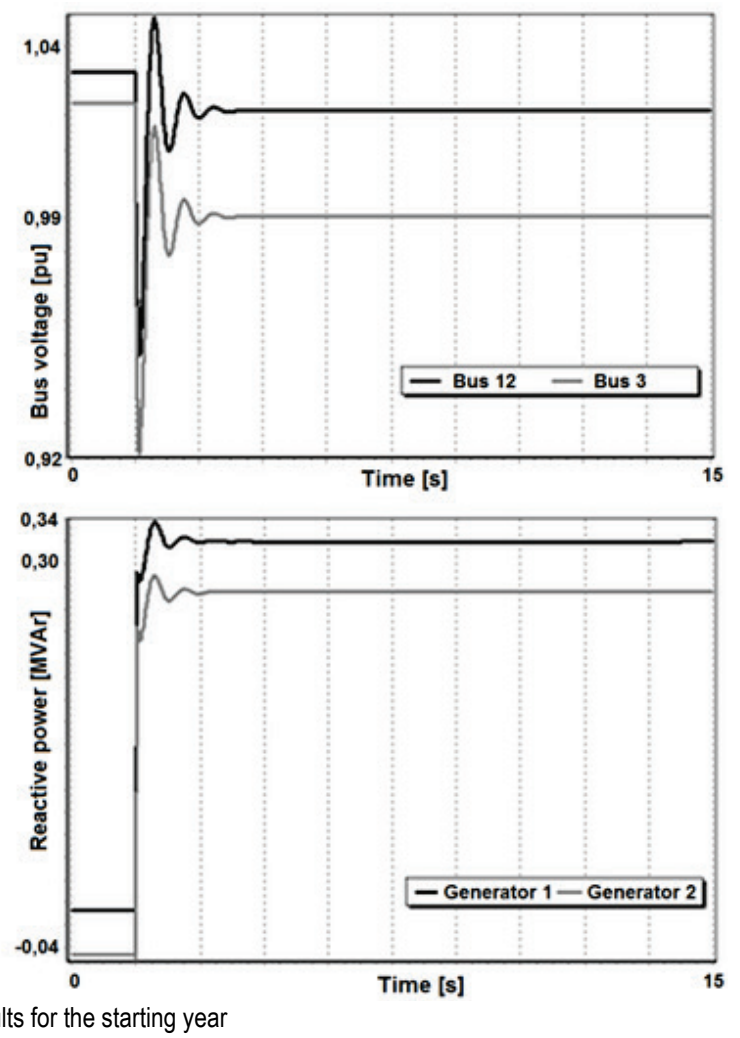

infinite bus blackout, the inductive load increases and both generators work in inductive mode. Generators active powers increase as they fully supply all remaining loads. Speed regulation ensures that generators remain in synchronism and operate at the nominal frequency of 50 Hz. Bus voltages slightly drop, but remain in the acceptable range of $\pm 5 \%$. The lowest voltage level is present at the furthest bus from the biogas plant, i.e. Bus 3.

Simulation results for the fifth year of observation, Fig. 5, show that, due to inductive load increase, the starting operating point for both generators is now in inductive mode. Again, after blackout real and reactive powers of both generators increase as the biogas plant fully supplies all remaining loads. Generators in the islanded mode stay in synchronism. After the blackout bus voltage drops are larger than in case of the starting year, but are still in the acceptable range. 
Simulation results for the tenth year of observation shown in Fig. 6 prove that with further energy consumption increase real and reactive powers of both generators additionally increase, as well as bus voltages drops. Generators still stay in synchronism and bus voltages remain in the acceptable range. Further increase of energy consumption in the biogas plant surrounding electrical grid leads to limits of permissible operating area of the generators in case of the islanded mode in the fifteenth year of observation, Fig. 7. Generators active powers are at maximum allowed level. Further energy consumption increase would lead to generator overheating and outage. Voltage drop of $5 \%$ at the furthest bus also equals maximum allowed voltage drop.

As expected, after the blackout in the twentieth year of observation generators are overloaded and cannot supply local consumers any more, Fig. 8. Frequency drop of more than $1 \mathrm{~Hz}$ leads to unstable operation and generators outage 0,4 seconds after the blackout occurs. Accordingly, generators real and reactive powers drop to zero, as well as all bus voltages.
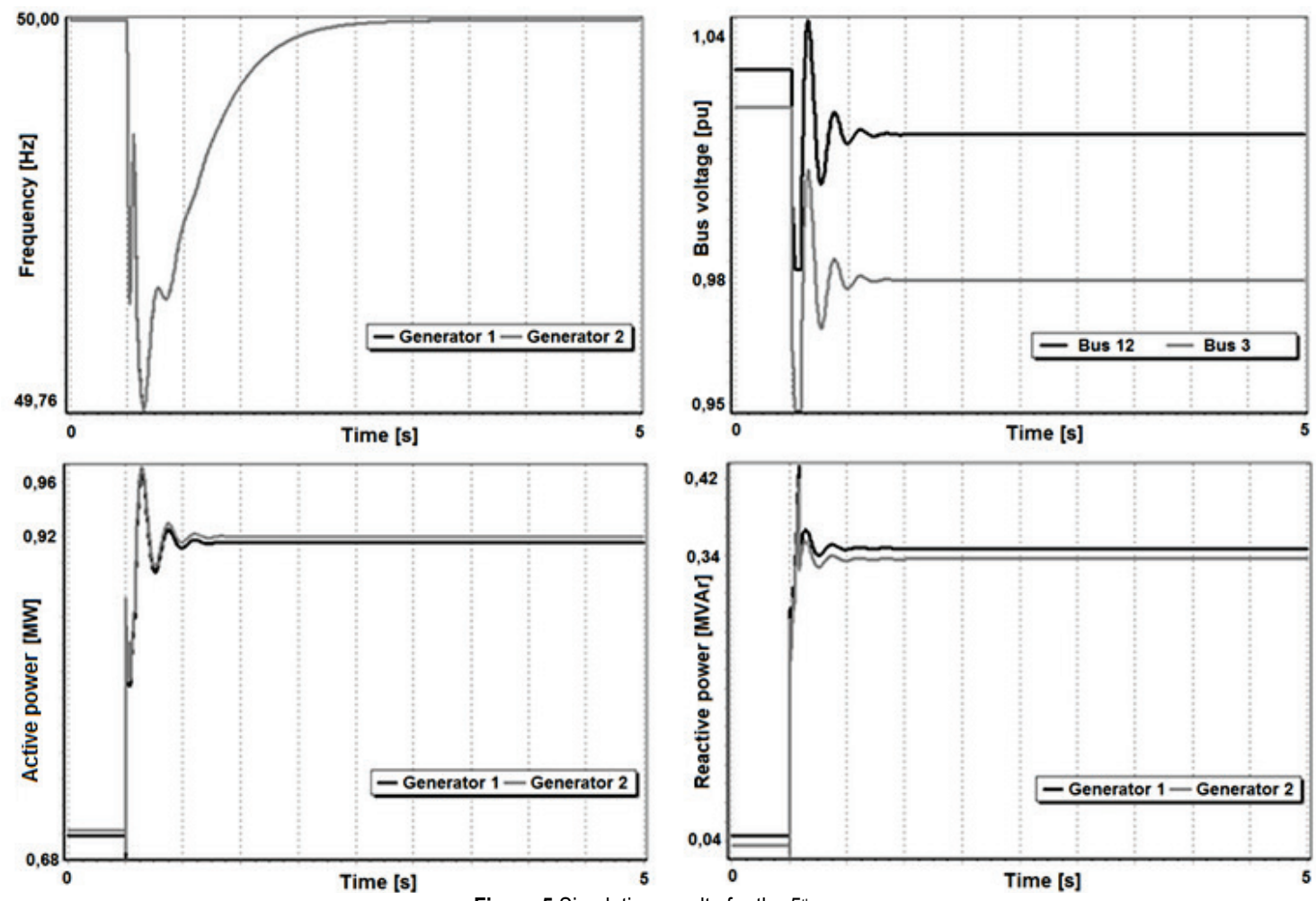

\subsection{Stability and Protection Analysis}

Simulations show that the modelled generators can supply local consumers with predicted load growth for the period of the next 15 years. In this period all frequencies and voltages remain in acceptable limits, as well as the overvoltage and undervoltage values. In electrical grids this protection is normally set in range of 0,5 to $1 \mathrm{~Hz} / \mathrm{s}$. As the level of generator inertia influences the frequency gradient and transient frequency values during a system incident [25], and simulated generators have the small inertia, there can be some issues regarding the Rate of Change of Frequency ( $R o C o F)$ protection. In electrical grids this protection is normally set in range of 0,5 to 1 $\mathrm{Hz} / \mathrm{s}$. For smaller generating units with the possibility of island mode operation, the maximal $\mathrm{RoCoF}$ is calculated in the following way [25]:

$R o C o F_{\text {max }}=\frac{\Delta P_{\text {Imbalance }}}{P_{\text {Load }}} \frac{f_{0}}{T_{N}}$,

where $\Delta P_{\text {Imbalance }}$ is the load power imbalance, $P_{\text {Load }}$ is the load active power and $f_{0}$ is the base frequency. The network time constant $T_{N}$ is calculated as follows [25]:

$$
T_{N}=\frac{\sum_{1}^{n} T_{A, S G, n} P_{N o m, S G, n}}{P_{\text {Load }}} .
$$

The acceleration time constant $T_{A, S G, n}=J \Omega_{n}^{2} / P_{N o m, S G, n}$ is calculated for each generator knowing its inertia $J$, nominal angular velocity $\Omega_{n}$ and nominal power $P_{N o m, S G, n}$. The maximal and recorded $R o C o F$ values for simulated microgrid are given in Tab. 3 .

Table 3 Maximal and simulated RoCoF per years

\begin{tabular}{|c|c|c|}
\hline Simulation year & $R o C o F_{\max } / \mathrm{Hz} / \mathrm{s}$ & $R o C o F / \mathrm{Hz} / \mathrm{s}$ \\
\hline 0 & 7,20 & 0,42 \\
\hline 5 & 8,38 & 2,84 \\
\hline 10 & 9,84 & 10,08 \\
\hline 15 & 11,38 & 22,4 \\
\hline
\end{tabular}

The results presented in Tab. 3 show how the $R o C o F$ protection should be set depending on expected load in island mode, and what $R o C o F$ can be expected. It can be seen that $R o C o F$ protection would not let the generators operation in given islanded mode even for the tenth year of simulation. 
The power imbalance effect on the main grid (Bus1) cannot be observed with the given simulation model, as the grid impedances and inertia are not modelled. However, since the main grid power is significantly larger than the power of disconnected microgrid, the transient
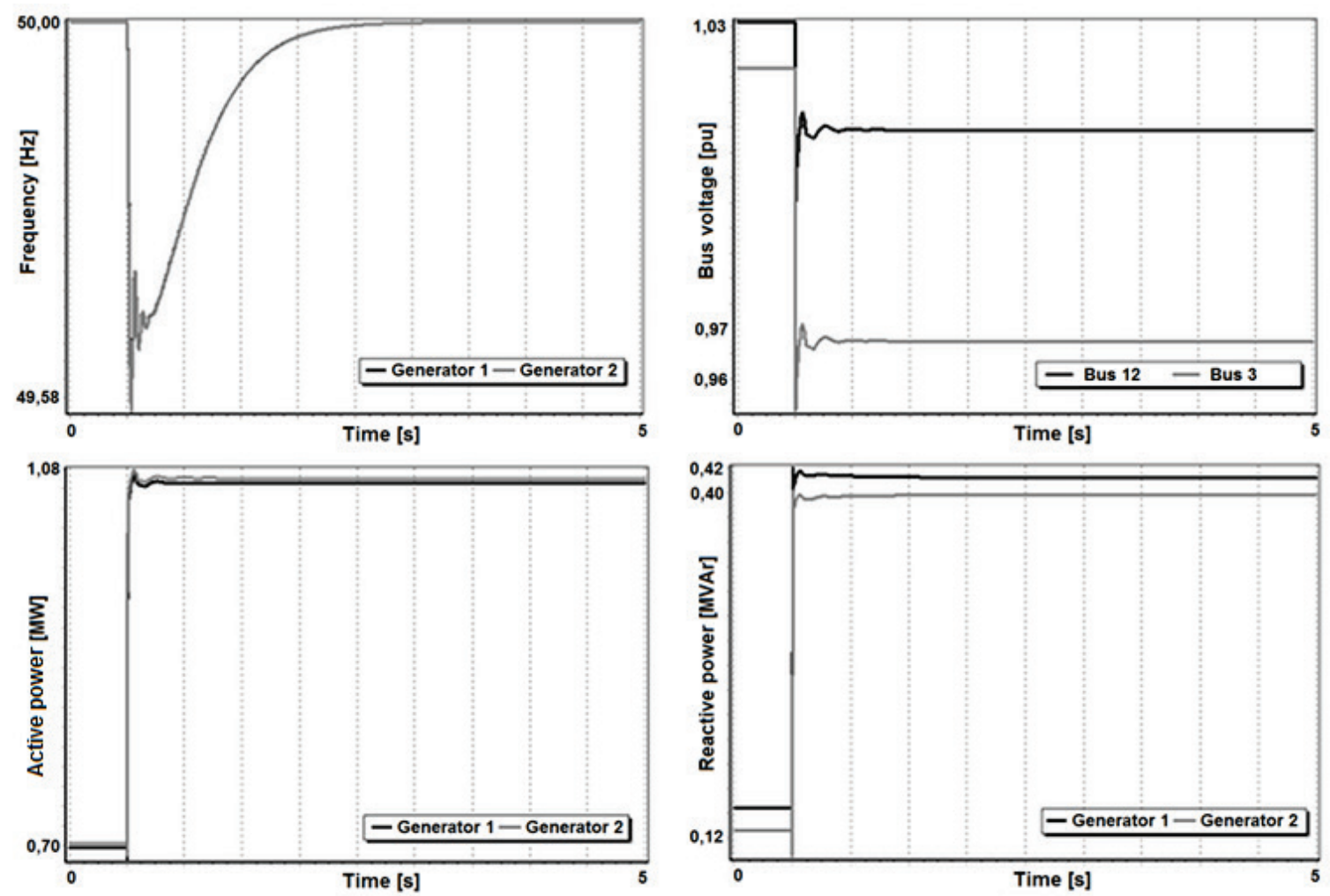

Figure 6 Simulation results for the 10th year
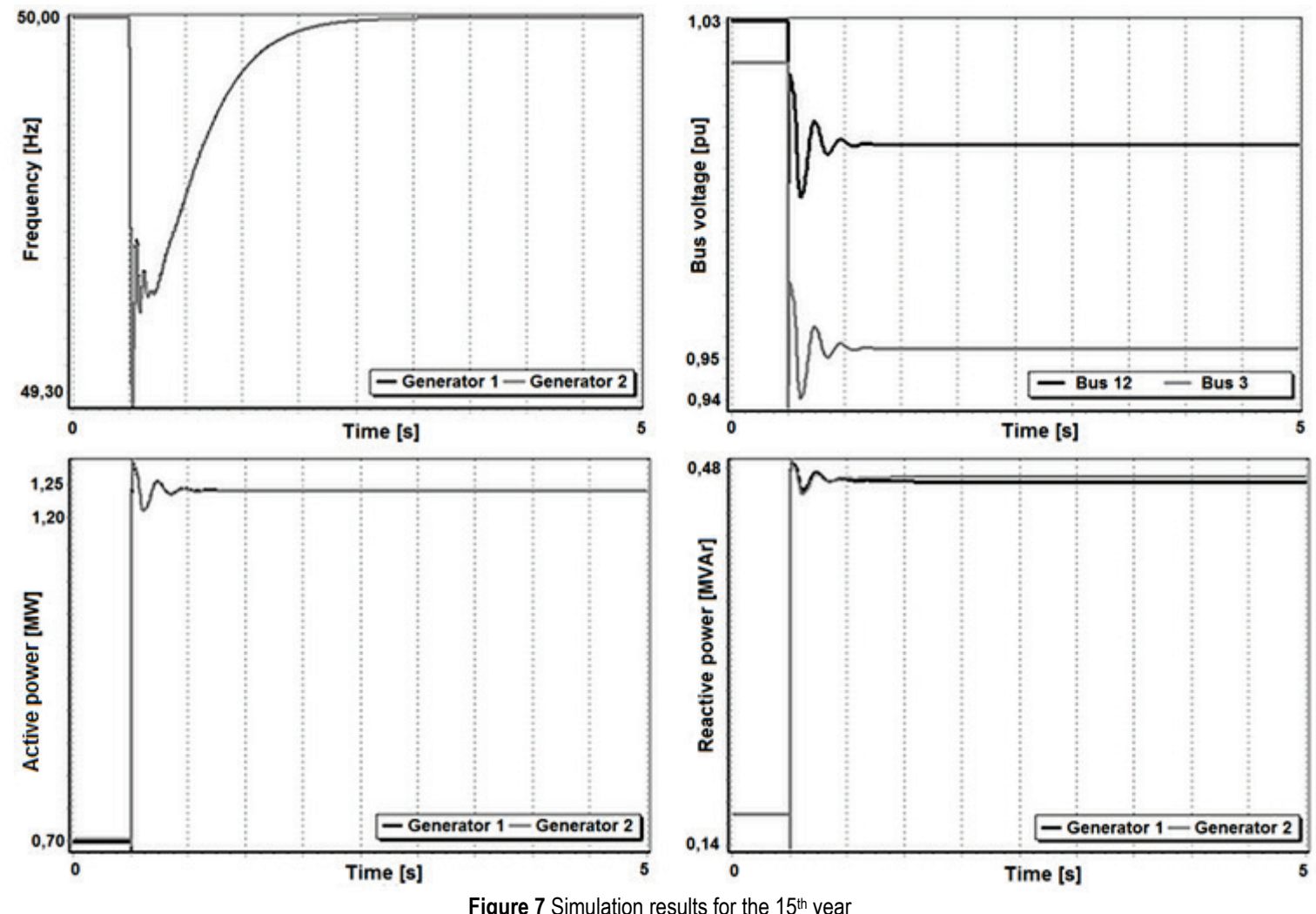

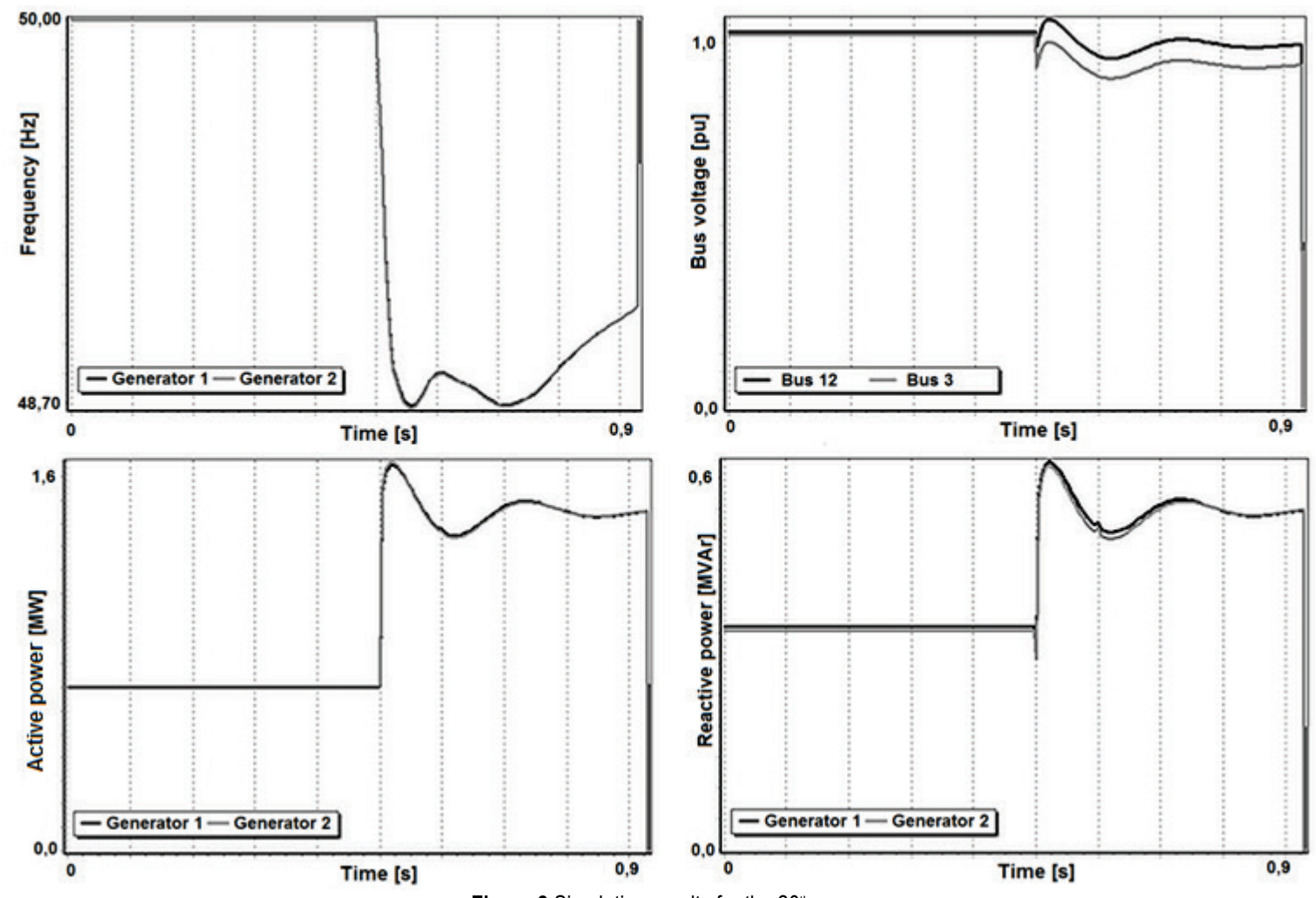

Figure 8 Simulation results for the $20^{\text {th }}$ year

\section{CONCLUSION}

In this paper islanded operation of a microgrid containing biogas plant with surrounding consumers is modelled and simulated. Stability testing is carried out by comprising models of generator, driving machine, control units and electrical grid together with modelling of energy consumption growth. Energy consumption growth is modelled by geometric progression with the annual rate of $3,5 \%$. This multimachine model is implemented in Power World Simulator for the transient stability analysis.

Simulation results show that tested biogas plant can operate in the islanded mode being stable and high quality supply to the surrounding consumers in the next ten years. In the case of island mode occurring in the tenth year, the RoCoF protection would activate, but the system is still stable. In the fifteenth year of observation generators operating points reach stability margin. Further increase of energy consumption leads to instability in islanded operating mode and generators outages.

Stability analysis presented in the paper leads to conclusion that the islanded operation mode for the tested biogas plant is possible and acceptable in the next ten years. To enable islanded operation mode after that year, biogas plant production capacity should be extended by introducing the third cogeneration facility.

As gained simulation results present the system transient response, in the future harmonic analysis as in [26] should be carried out. Another issue that arises when dealing with small biogas plant islanded operation is the problem of resynchronization to the electric power system after clearing a blackout. This means that further work should contain analysis of transient stability in case of resynchronization to the electric power system.

\section{REFERENCES}

[1] Panwar, N. L., Kaushik, S. C., \& Kothari, S. (2011). Role of renewable energy sources in environmental protection: A review. Renewable \& Sustainable Energy Reviews, 15(3), 1513-1524. https://doi.org/10.1016/j.rser.2010.11.037

[2] Krajnc, M. \& Dolsak, B. (2013). Computer and Experimental Simulation of Biomass Production Using Drum Chipper. International Journal of Simulation Modelling, 12(1), 39-49. https://doi.org/10.2507//JSIMM12(1)4.223

[3] Pipatmanomai, S., Kaewluan, S., \& Vitidstant, T. (2009). Economic assessment of biogas-to-electricity generation system with $\mathrm{H} 2 \mathrm{~S}$ removal by activated carbon in small pig farm. Applied Energy, 86(5), 669-674. https://doi.org/10.1016/j.apenergy.2008.07.007

[4] Tippayawong, N., Promwungkwa, A., \& Rerkkriangkrai, P. (2007). Long-term operation of a small biogas/diesel dualfuel engine for on-farm electricity generation. Biosystems Engineering, 98(1), 26-32. https://doi.org/10.1016/j.biosystemseng.2007.06.013

[5] Carrasco, J. M., Franquelo, L. G., Bialasewicz, J. I., Galvan, E., Portillo Guisado, R. C., Martin Prats, M. A., Leon, J. I., \& Moreno-Alfonso, N. (2006). PowerElectronic Systems for the Grid Integration of Renewable Energy Sources: A Survey. IEEE Transactions on Industrial Electronics, 53(4), 1002-1016. https://doi.org/10.1109/TIE.2006.878356

[6] Ustun, T. S., Ozansoy, C., \& Zayegh, A. (2011). Recent developments in microgrids and example cases around the world - A review. Renewable \& Sustainable Energy Reviews, 15(1), 4030-4041. https://doi.org/10.1016/j.rser.2011.07.033

[7] Chowdhury, S. P., Chowdhury, S., \& Crossley, P. A. (2009). Islanding protection of active distribution networks with renewable distributed generators: A comprehensive survey. Electric Power Systems Research, 79(6), 984-992. https://doi.org/10.1016/j.epsr.2008.12.012 
[8] Xiaozhi, G., Linchuan, L., \& Wenyan, C. (2011). Power Quality Improvement for Mircrogrid in Islanded Mode. Procedia Engineering, 23, 174-179. https://doi.org/10.1016/j.proeng.2011.11.2485

[9] Di Fazio, A. R., Fusco, G., Russo, M., Valeri, S., Noce, C., \& Amura, G. (2015). A smart device for islanding detection in distributed system operation. Electric Power Systems Research, 120(3), 87-95. https://doi.org/10.1016/j.epsr.2014.08.002

[10] Logenthiran, T., Srinivasan, D., Khambadkone, A. M. (2011). Multiagent system for energy resources scheduling of integrated microgrids in a distributed system. Electric Power Systems Research, 81(1), 138-148. https://doi.org/10.1016/j.epsr.2010.07.019

[11] Zeng, Z., Yang, H., \& Zhao, R. (2011). Study on small signal stability of microgrids: A review and a new approach. Renewable \& Sustainable Energy Reviews, 15(1), 4818-4828. https://doi.org/10.1016/j.rser.2011.07.069

[12] Lidula, N. W. A. \& Rajapakse, A. D. (2011). Microgrids research: A review of experimental microgrids and test systems. Renewable\& Sustainable Energy Reviews, 15(1), 186-202. https://doi.org/10.1016/j.rser.2010.09.041

[13] Jerković, V., Špoljarić, Ž., \& Šljivac, D. (2011). Stability Testing of a Small Biogas Plant in Electric Power System. International Journal of Electrical and Computer Engineering Systems, 2(2), 49-54.

[14] Machowski, J., Bialek, J. W., Robak, S., \& Bumby, J. R. (1998). Excitation control system for use with synchronous generators. Generation, Transmission and Distribution, IEE Proceedings, 145(5), 537-546. https://doi.org/10.1049/ip-gtd:19982182

[15] Qiao, W. \& Hui, Q. (2010), Energy-Based Hybrid Excitation Control for Synchronous Generators. Power and Energy Society General Meeting IEEE / Minneapolis, USA, $1-6$.

[16] Kundur, P., Paserba, J., Ajjarapu, V., Andersson, G., Bose, A., Canizares, C., Hatziargyriou, N., Hill, D., Stankovic, A., Taylor, C., Van Custem, T., \& Vittal, V. (2004). Definition and Classification of Powewr System Stability. IEEE/CIGRE Joint Task Force on Stability Terms and Definitions, IEEE Transactions on Power Systems, 19(3), 1387-1401. https://doi.org/10.1109/TPWRS.2004.825981

[17] Eberly, T. W. \& Schaefer, R. C. (2002). Voltage versus $\mathrm{VAr} /$ power-factor regulation on synchronous generators. IEEE Transactions on Industry Applications, 38(6), 16821687. https://doi.org/10.1109/TIA.2002.805560

[18] Navrátil, P. \& Balátě, J. (2011). Simulation of Control of Multi-Variable Control Loop: Steam Turbine. International Journal of Simulation Modelling, 10(2), 53-65. https://doi.org/10.2507/IJSIMM10(2)1.167

[19] Renewables 2017 Global Status Report. Paris: REN21 Secretariat. http://www.ren21.net/wp-content/uploads/2017/ 06/GSR2017 Full-Report.pdf (13.10.2017)

[20] Suganthi, L. \& Samuel, A. A. (2012). Energy models for demand forecasting - A review. Renewable \& Sustainable Energy Reviews, 16(2), 1223-1240. https://doi.org/10.1016/j.rser.2011.08.014

[21] Ekonomou, L. (2010). Greek long-term energy consumption prediction using artificial neural networks. Energy, 35(2), 512-517. https://doi.org/10.1016/j.energy.2009.10.018

[22] Kankal, M., Apkinar, A., Kömürcü, M. I., \& Özşain, T. S. (2011). Modeling and forecasting of Turkey's energy consumption using socio-economic and demographic variables. Applied Energy, 88(5), 1927-1939. https://doi.org/10.1016/j.apenergy.2010.12.005

[23] Sadorsky, P. (2011). Financial development and energy consumption in Central and Eastern Europian frontier economies. Energy Policy, 39(2), 999-1006. https://doi.org/10.1016/j.enpol.2010.11.034

[24] Pisupati, S. (2014). Energy Supply and Demand, course lesson, The Pennsylvania State University. https://www.eeducation.psu.edu/egee102/node/1929. (10.02.2016)

[25] Frequency Stability Evaluation Criteria for the Synchronous Zone of Continental Europe - Requirements and Impacting Factors. European Network of Transmission System Operators for Electricity. March 2016. https://www.entsoe.eu/Documents/SOC\%20documents/RG CE SPD frequency stability criteria v10.pdf (13.10.2017)

[26] Špoljarić, Ž., Jerković, V., \& Stojkov, M. (2012). Measurement System for Transformer Inrush Current Higher Harmonics Determination. Annals of DAAAM for 2012 \& Proceedings of the 23rd International DAAAM Symposium / Zadar, Croatia, 617-622.

\section{Contact information}

dr. sc. Vedrana JERKOVIĆ ŠTIL, dipl. ing. el. Faculty of Electrical Engineering, Computer Science and Information Technology Osijek Kneza Trpimira 2B, 31000 Osijek, Croatia vedrana.jerkovic@etfos.hr

dr. sc. Željko ŠPOLJARIĆ, dipl. ing. el. Faculty of Electrical Engineering, Computer Science and Information Technology Osijek Kneza Trpimira 2B, 31000 Osijek, Croatia zeljko.spoljaric@etfos.hr

izv. prof. dr. sc. Željko HEDERIĆ, dipl. ing. el. Faculty of Electrical Engineering, Computer Science and Information Technology Osijek Kneza Trpimira 2B, 31000 Osijek, Croatia hederic@etfos.hr 